\title{
REVISTA'
}

de la

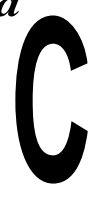

E

PAL

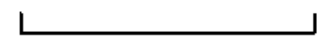

NUMERO 63

DICIEMBRE 1997

SANTIAGO DE CHILE

OSCAR ALTIMIR

Director

EUGENIO LAHERA

Secretario Técnico

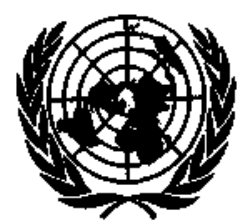

NACIONES UNIDAS 
El papel del sector público en el desarrollo latinoamericano

Ricardo Carciofi

La equidad en el presupuesto público

Juan Martin

Reformas a los sistemas de pensiones, mercado de capitales y ahorro

Andras Uthoff

Institucionalidad pública y políticas ambientales explícitas

e implícitas

Nicolo Gligo

La valoración de recursos naturales y ambientales no basada en el mercado en Centroamérica y el Caribe

Steve Shultz

Un modelo macroeconómico integrado para el Caribe

Lucio Vinhas de Souza

Virajes y derrapajes de la economía venezolana

José Miguel Benavente

¿Cuán no tradicionales son las exportaciones no tradicionales?

La experiencia de siete países de la Cuenca del Caribe

Alberto Gabriele

Apertura comercial y cambio estructural en la industria automotriz brasileña

Ruy de Quadros Carvalho, Sergio Robles Reis de Queiroz,

Flávia Luciane Consoni, loriara Costa y Janaína Pamplona da Costa

Historia evolutiva de una planta metalmecánica chilena

Jorge Katz y Héctor Vera

La importancia de la producción local y la pequeña empresa para el desarrollo de América Latina

Francisco Alburquerque

Publicaciones recientes de la CEPAL 


\section{Virajes y derrapajes de la economía venezolana}

\section{José Miguel Benavente}

\section{Economista}

División de Desarrollo

Económico, CEPAL
Cuando el modelo económico neoliberal, con cuya vigencia expira el milenio en América Latina, cumple ya algunos años de aplicación, se hace más oportuno evaluar la experiencia acumulada hasta la fecha. A esta tarea se abocan los economistas, desgranando y analizando las diversas características y componentes de los programas aplicados en los distintos países. Un aspecto a menudo descuidado en tales evaluaciones es el de la viabilidad social y política de las medidas adoptadas, que no depende sólo de la valoración técnica de ellas. La aceptación de tales medidas por los diversos sectores de la población ha pasado a ser igualmente importante, en particular tras la sustitución de regímenes militares por sistemas democráticos que obligan a tener más en cuenta la voluntad popular. Esto es lo que cabría llamar el factor "social" (o tal vez incluso "sicosocial") de la reforma. Una mejor comprensión de las variables que inciden en la reacción popular ante las medidas de política económica aplicadas facilitaría la evaluación previa de sus posibilidades de éxito. Para ello se cuenta ya con un acervo de experiencia en los distintos países. Una de las más interesantes es, tal vez, la que se desprende de la reiterada aplicación del modelo en Venezuela. La variada reacción de la población de ese país a los dos programas de corte neoliberal en 1989 y 1996 bien pudiera deberse a la distinta evolución de las magnitudes reales de la economía (crecimiento del producto y empleo), pese a la similitud existente entre los desequilibrios macroeconómicos en ambos casos. 


\section{I}

\section{La resistencia al cambio}

Los últimos años han sido testigos de importantes cambios económicos, sociales y políticos en América Latina. Comenzando con los países del Cono Sur en el decenio de 1970, los gobiernos han ido abandonando progresivamente las políticas económicas basadas en la sustitución de importaciones y modelos de desarrollo sustentados en el mercado interno para aplicar reformas e inaugurar políticas inspiradas en la doctrina económica neoliberal, de creciente influencia planetaria. Los países respondían así tanto a circunstancias internas, principalmente las limitaciones de las estrategias aplicadas hasta entonces, como externas, derivadas de las posibilidades y exigencias de la aceleración del comercio y de las corrientes de inversión mundiales. La crisis de la deuda de los años ochenta fue un catalizador importante de este proceso.

Con el término neoliberalismo se hace aquí referencia a la doctrina económica que, en lo esencial, apoyándose en la premisa de que funcionamiento del mercado y poder del Estado están inversamente relacionados, propugna una menor intervención del segundo para potenciar las virtudes del primero. En este sentido, enlaza con su antecedente decimonónico. ${ }^{1}$ En su versión actual, el inventario neoliberal está bien representado en lo que se ha dado en llamar el Consenso de Washington, ${ }^{2}$ avalado por muchas de las instituciones (públicas y privadas) que tienen su sede en esa capital (Fondo Monetario Internacional, Banco Mundial y gobierno e instituciones de los Estados Unidos, sobre todo). Tal Consenso agrupa recetas de política eco-

\footnotetext{
${ }^{1}$ Una interesante diferencia entre el antiguo liberalismo y el moderno neoliberalismo es que el primero encontró oposición en el mundo en desarrollo de su época, es decir, en los trece jóvenes estados del Norte de América que acababan de lograr su independencia de la Gran Bretaña, mientras que el segundo, cuyos paladines son ahora aquellos mismos estados convertidos en primera potencia mundial, ha llegado a ser aceptado igualmente por los países periféricos. Al respecto, véase la reedición del clásico estudio de Clairmont (1996) que ofrece una provocativa exposición del desarrollo histórico del liberalismo. Para quienes interpretan la economía en su contexto histórico vinculado con el mundo real de las fuerzas productivas, esta diferencia está sin duda relacionada con los imperativos de la mayor mundialización característica de nuestros días. Esta última explicación se argumenta, por ejemplo, en Vacs (1994).

${ }^{2}$ Véase Williamson (1990) y Williamson, ed. (1994).
}

nómica, consideradas ya "ortodoxas", en torno a los grandes ejes de la estabilización macroeconómica, la desregulación de los mercados, la reducción de las barreras a los intercambios externos y la privatización de los activos estatales.

En el actual neoliberalismo, al igual que en su antecesor, los aspectos distributivos están lejos de ocupar el centro de las preocupaciones y del análisis. ${ }^{3}$ A menudo, esta carencia ha limitado crucialmente la aplicabilidad del modelo, pues lo divorcia de una realidad en que aquellos aspectos son insoslayables. Es cierto que en la formulación inicial del Consenso de Washington se incluía algún elemento con cierta trascendencia social, como la priorización del gasto público en materia de salud y educación; y que, además, en años recientes se ha ido generando un consenso sobre la necesidad de una segunda generación de reformas (o "Consenso de Washington mark II" $)^{4}$ que tenga más en cuenta los aspectos sociales y la distribución de los beneficios de la reforma para afianzar la estabilidad política, junto con reforzar la institucionalidad del Estado. ${ }^{5}$ Sin embargo, estas consideraciones, aunque ciertamente valiosas, tienen que ver con el mediano y largo plazo, y no necesariamente con el costo social inmediato de las políticas aplicadas, el cual puede hacer imposible la necesaria estabilización de una economía,

\footnotetext{
3 ¿Podría acaso aplicarse al nuevo liberalismo la calificación que hiciera Keynes del antiguo, cuando, refiriéndose a la doctrina ricardiana, afirmaba que "Le otorgó virtud el hecho de que sus enseñanzas, llevadas a la práctica, eran austeras y a veces desabridas; le dio belleza el hecho de que fuera compatible con una superestructura lógica vasta y consistente; le prestó autoridad el hecho de que podía explicar mucha injusticia social y aparente crueldad como un accidente inevitable en la marcha del progreso y que el intento de cambiar estas cosas tenía, en términos generales, más probabilidades de causar daño que beneficio"? (Keynes, 1936, reimpresión sin fecha, p. 33). La traducción es propia.

${ }^{4}$ The Economist Intelligence Unit (1997).

${ }^{5}$ Una influencia notable sobre esta evolución proviene probablemente de la CEPAL, que ha señalado reiteradamente que el énfasis puesto por el proceso de liberalización económica en el crecimiento del producto y la reducción de la inflación no es suficiente ya que el crecimiento por sí solo no puede garantizar mejores efectos distributivos, lo que explica el panorama social poco alentador que se observa en América Latina y que puede dificultar el sostenimiento del proceso de desarrollo (CEPAL, 1997).
} 
independientemente de lo acertadas que sean dichas políticas en una perspectiva temporal más amplia. ${ }^{6}$

El objetivo de este artículo no es llevar a cabo una evaluación de tipo normativo sobre las políticas económicas neoliberales en general, sino explorar un aspecto de la tensión que puede surgir entre el cumplimiento de su presupuesto básico, en particular en lo que se refiere al funcionamiento objetivo de los mercados, y las condiciones reales de su aplicación, vinculadas con el contexto social en que ésta se efectúa, cuando la reacción popular a las políticas pasa a ser decisiva para determinar la viabilidad de ellas.

\section{La reacción popular a las reformas}

Las políticas neoliberales llevaban consigo cambios radicales en el equilibrio de intereses económicos entre los distintos estratos de la sociedad. El ciudadano común no podía permanecer indiferente ante estos cambios, que le afectaban directamente en sus múltiples facetas de consumidor, trabajador asalariado, empleador, inversionista, ahorrador, etc, y que por lo tanto incidían directamente en sus condiciones de vida. Sin embargo, en general el cambio del entorno económico no dio lugar inmediatamente a fuertes resistencias por parte de los sectores de población desfavorecidos por aquel reequilibrio.

Es cierto que las primeras experiencias (en Chile, Argentina) tuvieron lugar en el marco de regímenes militares autoritarios que hacían difícil, si no imposible, la expresión de descontento de quienes se veían adversamente afectados. Comenzando por Chile, primer país que persistió en la aplicación de reformas estructurales neoliberales, la falta de libertades impidió que el costo social soportado por amplios sectores tuviera una manifestación política decisiva. Sin embargo, tras el retorno de los países latinoamericanos a sistemas políticos formalmente democráticos, los gobiernos siguieron aplicando reformas sin incurrir en la oposición activa y generalizada de sus ciudadanos. ${ }^{7}$

\footnotetext{
${ }^{6}$ Otros autores han señalado lo mismo. Bresser, Maravall y Przeworski (1994, p.182), por ejemplo, afirman que "Los intentos de estabilización ... generan costes sociales que hacen la continuación de las reformas políticamente desagradables en un contexto democrático. Además, el estilo tecnocrático en que tienden a formularse y aplicarse esas políticas socava la consolidación de las instituciones democráticas" (traducción propia). Para matizar esta afirmación general es útil la distinción que hacen Haggard y Kaufman (1995) de dos fases, de iniciación y de consolidación, de las reformas.

${ }^{7}$ El fenómeno de la adopción de reformas de este tipo en regímenes democráticos ha suscitado diversas explicaciones teóricas de lo que
}

México, Bolivia, Colombia, Perú, Brasil, transitaron por esa vía sin descarrilar en el camino. Tan sólo posteriormente, al recrudecer las tensiones sociales, se elevaron voces que se hacían eco de los desfavorecidos de la reforma. En México, Honduras, Bolivia, Argentina, esas voces han ido poco a poco haciéndose más estridentes. Luego han surgido, en fecha más reciente, cónclaves (en Chiapas, en Montevideo) donde se ha puesto abiertamente en entredicho el paradigma neoliberal en sus diversas aplicaciones latinoamericanas.

Estas manifestaciones de rechazo han abarcado, de norte a sur de la región, una gran variedad de sectores y de instancias, orgánicas e inorgánicas, representativas directa o indirectamente de estamentos populares. Por ejemplo, la XXIX Conferencia de la Confederación Latinoamericana de Religiosos, celebrada en noviembre de 1996 en Tegucigalpa, denunció el modelo económico neoliberal como una causa de la pobreza que agobia a la región. En parecido sentido se han pronunciado diversos obispos y arzobispos centroamericanos (por ejemplo, de El Salvador y Honduras). ${ }^{8}$ En el otro extremo del continente, organizaciones sindicales de los países del Mercosur identificaban al neoliberalismo como la causa del deterioro de las condiciones de vida de los trabajadores. ${ }^{9}$ En lo que respecta en particular a las privatizaciones, uno de los ingredientes básicos del recetario neoliberal, en Uruguay en 1992 y en Ecuador en 1995 la población rechazó en sendas consultas populares la transferencia al sector privado de la compañía de teléfonos y de la seguridad social, respectivamente. En una reunión previa a la Asamblea anual del Banco Interamericano de Desarrollo, que tuvo lugar en Barcelona en marzo de 1997, varios alcaldes de ciudades latinoamericanas pusieron en tela de jucio el proceso de privatización de servicios públicos.

Se ha ido generando, pues, una corriente de opinión en el sentido de que la aplicación de políticas neoliberales habría redundado en un aumento de la desigualdad e incluso de la pobreza, el recrudecimiento consiguiente de la criminalidad en las grandes ciudades y hasta una agudización de la violencia política que

\footnotetext{
Navarro (1995) considera la "anomalía" de la tolerancia popular a los procesos de ajuste económico, explicaciones analizadas por este autor.

${ }^{8}$ En Honduras se han declarado en contra de los efectos sociales del neoliberalismo, además de la Iglesia Católica, instituciones tan representativas como los sindicatos y el Colegio de Economistas.

${ }^{9}$ En este sentido, los sindicatos de los cuatro países de la agrupación realizaron una jornada de protesta coordinada en diciembre de 1996.
} 
sufren algunos países donde existen movimientos guerrilleros (como Perú, Colombia y México).

En una era de nuevos regímenes democráticos, esta percepción de la gente constituye un elemento crucial que debe ser tenido en cuenta a la hora de aplicar reformas de política económica. El factor social ha adquirido en este contexto un peso político cierto. Se ha argumentado que la adopción de aquellas políticas se ha vuelto más difícil en ausencia de los anteriores gobiernos autoritarios y que la misma ha llevado consigo una tendencia hacia lo que se podría considerar un cierto comportamiento autocrático en el seno de los nuevos regímenes democráticos. ${ }^{10}$ En este sentido pueden interpretarse la concesión de poderes extraodinarios por los parlamentos de Argentina y Brasil a sus respectivos presidentes y la disolución del congreso por parte del presidente del Perú. En otros países, dicho factor social puede haber operado en contra de presidentes en posición más débil; los ejemplos a este respecto incluyen las separaciones del cargo de los presidentes de Guatemala y, más recientemente, del Ecuador, así como de Venezuela, al que se alude más adelante. El presidente de Honduras, quien en 1994 comenzó a aplicar un esquema económico neoliberal, declaraba en abril de 1997 no haber firmado una carta de intención con el Fondo Monetario Internacional debido a la dureza de las medidas que habría tenido que aplicar.

Esta evolución obliga a tener en cuenta las circunstancias sociales de los países en el diseño y la aplicación de las políticas económicas para que éstas sean políticamente viables." En particular, la reacción de la población, o factor social, es determinante. Resulta plausible, por ejemplo, que la destitución del presidente del Ecuador por el congreso de su país se debiera en gran medida a la rapidez con que trató de

\footnotetext{
${ }^{10}$ En estos términos se expresan, por ejemplo, Haggard y Kaufman (1995, p. 360), quienes indican además que "En México, el sistema de representaciones de intereses de tipo corporatista también jugó un papel importante, pero dentro también de un contexto institucional autoritario" .Véase asimismo Heredia (1994) y Kaufman, Bazdresch y Heredia (1993) sobre México, así como Cavarozzi (1994) sobre la relación entre reformas y regímenes autoritarios. Algunos incluso se han planteado ante estas situaciones si las democracias latinoamericanas pueden entenderse "consolidadas" (véase, por ejemplo, Gamarra, 1994, Acuña y Smith, 1994).

${ }^{11}$ Esta necesidad ha sido señalada por varios autores. Rodrik (1996), por ejemplo, afirma en este sentido que "la mayoría de los economistas se ha dado ya cuenta de que una buena receta económica requiere comprender la economía política de la situación" (pág. 38, traducción propia). De Janvry, Fargeix y Sadoulet (1991) elaboran incluso un índice de "factibilidad política" de los resultados de la política económica.
}

aplicar un drástico programa de reforma para el que la población no estaba preparada.

Para explicar la reacción de la población a los programas de reforma, con frecuencia se alude a la importancia que reviste el contexto económico; ${ }^{12}$ un aspecto de este último se refiere al desempeño de la economía previo a la promulgación de las medidas, en particular cuando existen situaciones de crisis económica. Gamarra (1994), por ejemplo, no es el único que pone de relieve este factor cuando señala que "la experiencia de Bolivia y de Argentina - que no consiguieron estabilizar sus economías a comienzos del decenio de 1980 - sugiere que las duras medidas de austeridad sólo funcionan cuando la economía se ha hundido hasta tocar un nivel mínimo histórico". ${ }^{13}$ En esta misma línea, cabe suponer que la aceptación de programas similares en Argentina (una década más tarde), Brasil y Perú se apoyó en el fuerte rechazo de la población a la situación hiperinflacionaria anterior, la cual estuvo ausente en el Ecuador, ${ }^{14}$ al igual que en Venezuela. A este respecto, la experiencia de este último país, donde la aplicación de políticas neoliberales se ha enfrentado en dos ocasiones con distintas respuestas de la población, podría ser reveladora.

\section{Una experiencia peculiar: Venezuela}

En 1989 se produjo en el continente la primera excepción a la adopción pacífica del modelo neoliberal: en Venezuela, el anuncio de un paquete de drásticas medidas de ese corte fue acogido por la población con violentos disturbios que figuran entre los peores ocurridos en la historia del país. Precisamente, era Venezuela donde, en toda la región, el régimen de democracia formal tenía más larga vigencia; el último gobierno militar autoritario se remontaba a los años cincuenta y tres décadas más tarde la mayoría de los venezolanos había crecido en un régimen partidista y electoral respetuoso de la libertad de expresión.

Fueron esos mismos venezolanos los que en febrero de 1989 reaccionaron violentamente y en gran número ante el anuncio de las medidas económicas adoptadas por el gobierno del recién elegido presidente Carlos Andrés Pérez, medidas que se dieron a conocer bajo la etiqueta de El Gran Viraje de la economía venezolana. Aunque existen discrepancias sobre el

\footnotetext{
${ }^{12}$ La relación entre desempeño económico y tensiones sociopolíticas ha sido explorada por Acuña y Smith (1994).

${ }^{13}$ Gamarra, 1994, pág. 4 (traducción propia).

${ }^{14}$ Véase Latin American Weekly Report, 1997a.
} 
saldo contable de los disturbios callejeros, hay consenso sobre su gravedad: cientos de víctimas mortales y daños cuantiosos a la propiedad. Instantáneamente, la inmensa popularidad de que gozaba el presidente, quien había sido elegido dos meses antes con el margen más amplio del voto popular en 25 años, se tornó en uno de los mayores rechazos de que ha sido objeto un mandatario de ese país. Esta situación allanó el terreno para dos intentos de golpe de estado tres años después y finalmente para la separación de Carlos Andrés Pérez de su cargo en 1993 bajo acusaciones de corrupción.

La suerte política del presidente selló la suerte económica del programa de reformas. Aunque algunos componentes importantes, como la liberalización del comercio, perduraron, otros, como ciertas reformas fiscales, no sobrevivieron al imperativo de su aprobación por el Congreso o vieron su aplicación interrumpida a medio camino. En 1994, el presidente Rafael Caldera, electo en virtud de una plataforma de rechazo al programa económico de su antecesor, reaccionó a una crisis súbita del sistema financiero imponiendo controles de precios y de cambios en la mejor tradición anterior a 1989.

Superada en lo fundamental la crisis financiera y ante la persistencia de agudos desequilibrios en la economía, quince meses después, en abril de 1996, el mismo presidente anunciaba al país un retorno a la ortodoxia neoliberal mediante un programa de ajuste conocido como la Agenda Venezuela que, como el precedente, gozaba del aval y del respaldo financiero del Fondo Monetario Internacional. Esta vez, sin embargo, no se produjo la temida explosión social. Algo había cambiado en la la sociedad venezolana.

Resulta fácil hacer radicar ese cambio en lo que podría llamarse la sicología social del país. Tal mutación sicológica tiene, no obstante, raíces en la realidad económica. La observación paralela de las circunstancias que precedieron al anuncio de los dos programas de reforma podría arrojar luz sobre lo que Moisés Nairn, un antiguo ministro de industria del presidente Pérez, denomina el aspecto político de la aplicación del cambio económico. ${ }^{15}$

Esta observación, que se reseña en las páginas siguientes, entronca con las explicaciones sobre la influencia de las crisis económicas en la aceptación popular de la austeridad que llevan consigo las reformas y programas de estabilización. La experiencia de Venezuela permite trascender cierta ambigüedad inherente a estas explicaciones ${ }^{16}$ y muestra en particular que, de los diversos componentes del mosaico económico, la existencia de desequilibrios macroeconómicos (presiones sobre los precios y las cuentas externas) empuja a las autoridades a adoptar medidas correctivas, pero que es el desempeño de las variables reales (producto, empleo y poder adquisitivo de la población) el que condiciona la acogida de la gente a aquellas medidas. Cuando las presiones de ambos lados presentan momentáneamente vectores divergentes, el tejido social corre el riesgo de desgarrarse.

\section{II}

\section{Historia de dos ajustes: el contexto económico}

En Venezuela, los períodos previos a 1989 y 1996 se caracterizaron por graves desequilibrios macroeconómicos; en ambos se trató de reequilibrar la economía oponiendo medidas voluntaristas al funcionamiento de los mercados. Los desequilibrios se manifestaron en las áreas fiscal, monetaria y externa. Aunque con diferencias importantes, en ambas situaciones coexistían sustanciales déficit fiscales y de balanza de pagos, tipos de cambio sobrevaluados, presiones inflacionistas difícilmente contenidas y tasas de interés reales negativas. No obstante, tales coincidencias encubrían situaciones algo diferentes de la economía "real"; en particular, la variación coyuntural del pro- ducto y del empleo eran más claramente desfavorables en los meses anteriores a $1996 .{ }^{17}$ La mayor incidencia de estas últimas variables en la percepción de la población sobre la situación económica del país puede explicar sus distintas reacciones a los dos programas de ajuste, juntamente con otros factores, entre ellos la conciencia del fracaso de las medidas heterodoxas

\footnotetext{
${ }^{15}$ Véase en Nairn (1993) una lúcida descripción del programa de ajuste de 1989 y su contexto histórico.

${ }^{16}$ Señalada por Rodrik (1996).

${ }^{17}$ Véase CEPAL, Estudio Económico de América Latina y el Caribe (varios años).
} 
para resolver la crisis creciente de un país acostumbrado a la opulencia petrolera.

\section{Desequilibrios macroeconómicos}

Tanto en 1988 como en 1995, los desequilibrios que arrastraba la economía venezolana hacían perentoria la adopción de medidas de ajuste adecuadas. Aunque en contextos y con antecedentes distintos, en ambas ocasiones la pérdida de reservas internacionales había llegado a ser incontenible pese al control de cambios vigente, mientras que las presiones inflacionistas desbordaban los límites de la política de control de precios, alimentadas por el déficit de las cuentas públicas.

\section{a) El drenaje de las reservas internacionales}

Resulta adecuado comenzar a deshilar la madeja de embrollo macroeconómico venezolano por el sector externo. En Venezuela, la inserción en la economía mundial, que al igual que en otros países ha condicionado cada vez más sus opciones de política económica, tiene características peculiares debido a la dependencia del petróleo. Esta dependencia ha incidido de forma determinante en la estructura económica $\mathrm{y}$, por ende, en la trama social del país.

Los ingresos de exportación del preciado combustible constituían en 1988 más del $80 \%$ del valor total de las ventas externas y ése no era un año particularmente favorable en la volátil trayectoria que han exhibido los precios del crudo desde 1973. El gobierno central obtenía alrededor del $60 \%$ de sus recursos corrientes de la explotación estatal de los hidrocarburos. En 1995, la gravitación del petróleo en las exportaciones de bienes permanecía intacta $\mathrm{y}$, a pesar de la reciente diversificación de las fuentes de recaudación fiscal, el recurso aportaba aún la mitad del presupuesto de ingresos del gobierno (gráfico 1).

La importancia de estos ingresos en moneda extranjera para el financiamiento del Estado vincula fuertemente la política fiscal con la política cambiaria. Las variaciones de la cotización del bolívar se reflejan inmediatamente en la disponibilidad de recursos estatales para financiar el gasto en moneda local. La evolución del sector externo condiciona así la consecución de los equilibrios internos en mayor grado aún que en otros países.

Tanto en 1988 como en 1995, el balance de pagos era deficitario y el Banco Central de Venezuela (BCV) debía hacer frente a una pérdida continua de reservas internacionales. En 1988, la pérdida se pro-
GRAFICO 1

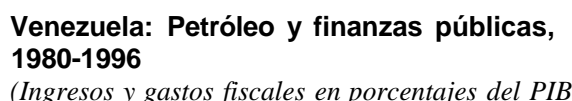

(Ingresos y gastos fiscales en porcentajes del PIB)

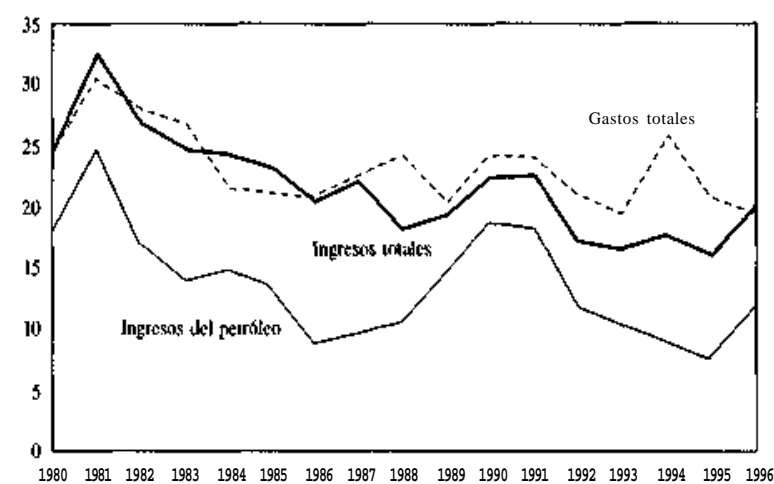

ducía por tercer año consecutivo y se acercaba al monto exorbitante de 4000 millones de dólares, el 30\% de las reservas existentes. En 1995, el drenaje de las reservas alcanzaba los 1900 millones de dólares, después de tres años de registros negativos. La posición de activos externos en poder del Banco Central era más crítica en 1988. En ambos años, las autoridades no pudieron evitar incurrir en atrasos en el servicio de su deuda externa.

Tales situaciones consagraban el fracaso de la política adoptada para preservar la capacidad de pago externa del país: el control de cambios a la tasa fijada oficialmente. Las restricciones a la libre disponibilidad de divisas contribuían a mantener los capitales externos alejados y propiciaban la fuga de los capitales internos. Las entradas de capital no podían compensar así la evolución desfavorable de las transacciones corrientes. En 1988, éstas se vieron agravadas por el descenso del precio del petróleo en los mercados internacionales, al contrario de lo sucedido en 1995, cuando la evolución de esos mercados favoreció los ingresos de exportación, contribuyendo a la obtención de un superávit comercial y de cuenta corriente. Esta última, en cambio, registró en 1988 un enorme déficit equivalente al $10 \%$ del PIB, impulsado por un saldo comercial de bienes negativo por primera vez en diez años.

El otro factor, común a los dos períodos, que incidió adversamente en las cuentas externas fue el auge aportado a las importaciones por el insostenible mantenimiento del tipo de cambio óficial, que redundó en una acumulación especulativa de inventarios estimulada por las expectativas de devaluación. En 1988, el valor de las compras externas se disparó en $24 \%$ y en 
1995 en 30\%, pese a la atonía de la actividad económica en este último año.

El sistema cambiario vigente en 1988 se basaba en una estructura de tipos de cambio oficiales múltiples cuyo nivel promedio alcanzaba a fines de año sólo la mitad del prevaleciente en el mercado paralelo. A fines de 1995 regía un único cambio oficial, devaluado en diciembre, tras haberse experimentado por un corto período con una paridad distinta para viajes, derivada de un virtual mercado libre implícito en las transacciones de bonos Brady cuya negociación había sido autorizada en la bolsa de Caracas. La relación entre la cotización oficial y la de este mercado libre representaba una sobrevaloración de la primera de más de $50 \%$, porcentaje que descendió a $18 \%$ tras la devaluación.

\section{b) El desequilibrio fiscal}

Pese a los enormes recursos generados para el fisco por las ventas del petróleo, las dificultades del gobierno para financiar sus gastos y obtener cuentas equilibradas se ha configurado como uno de los principales factores de desequilibrio macroeconómico en Venezuela. Frente a la rigidez de los gastos, la variabilidad e incertidumbre de los ingresos, dependientes de los volátiles mercados petroleros internacionales, han enfrentado al gobierno con la necesidad frecuente de endeudarse para cerrar la brecha entre unos y otros. En 1988, la expansión del gasto no pudo ser financiada con recursos ordinarios ante la desfavorable evolución de los ingresos del petróleo en dólares y el mantenimiento de un tipo de cambio sobrevaluado, pese a que la devaluación efectuada en 1987 había provocado un sustancial incremento de la recaudación en bolívares. Como consecuencia, tras dos años de cuentas ligeramente deficitarias el déficit fiscal se amplió considerablemente, llegando a representar el 5\% del producto interno bruto, nivel sin precedentes desde 1982 (gráfico 2).

La situación fiscal era aún más alarmante en 1995. La aguda crisis del sistema bancario desencadenada a fines de 1993 había obligado al Estado a intervenir un conjunto de entidades financieras al tiempo que suministraba ingentes recursos en concepto de auxilios a fin de evitar el derrumbe del sistema bancario. La emergencia financiera se saldó con desembolsos de unos dos billones de bolívares. En 1994, los aportes eran equivalentes al $13 \%$ del PIB y, aunque menores, siguieron gravando el presupuesto de 1995. Pese a los esfuerzos por obtener recursos fiscales adicionales y al alza del valor de las ventas de petróleo, el gobierno debió ano-
GRAFICO 2

Venezuela: El gobierno central en rojo, 1987-1996

(Resultadofinanciero en porcentajes del PIB)

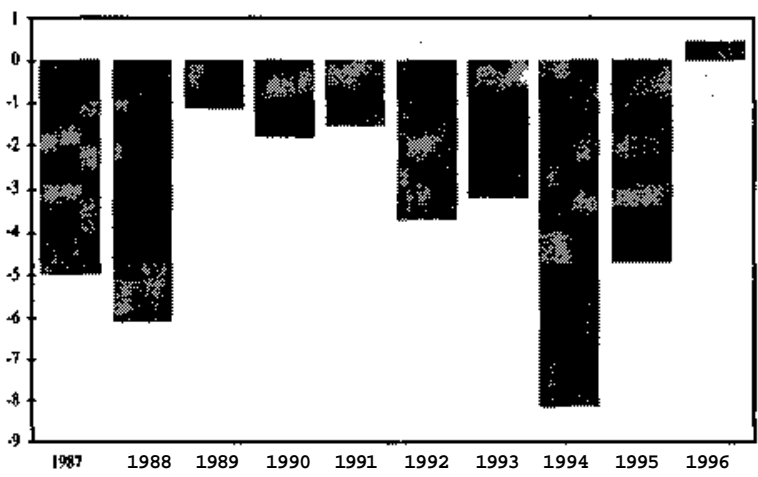

tar déficit equivalentes a 8\% y 5\% del PIB en 1994 y 1995, respectivamente. Los del sector público en su conjunto ascendieron a $14 \%$ y $6 \%$ del PIB en esos dos años.

Debido a las graves dificultades de acceder a los mercados crediticios internacionales señaladas anteriormente, así como a la limitación de los recursos disponibles en el mercado interior, esos déficit apenas pudieron financiarse mediante la colocación de títulos públicos. Fue necesario recurrir al crédito del Banco Central de Venezuela en grandes proporciones. En 1988, la mayor parte del déficit se financió mediante el uso de las reservas del Tesoro, que disminuyeron en casi $50 \%$ y llegaron a fin de año a su nivel más bajo de los cuatro años precedentes. El crédito del Banco Central al sector público también desempeñó un papel preponderante en la financiación de los déficit en 19941995. La expansión monetaria derivada de este modo de financiamiento sólo resultó parcialmente contrarrestada por la contracción de las reservas internacionales, obligando a menudo a costosas intervenciones por parte de la autoridad monetaria a fin de absorber la liquidez inyectada en el sistema. Esta última terminó agravando las presiones sobre los precios.

\section{c) El agravamiento de las presiones inflacionistas}

El financiamiento expansivo de los déficit fiscales generó presiones sobre los precios que acabaron con la trayectoria de baja inflación en Venezuela, un país que no había conocido los excesos hiperinflacionarios típicos de otros países latinoamericanos. En 1987, el alza de precios al consumidor alcanzó un nivel sin precedentes de $40 \%$, el cual sólo se redujo en cinco puntos porcentuales en el año siguiente, cuando la tasa 
de inflación duplicó el promedio registrado en el decenio de 1970. Peor aún fue la situación previa a 1996. El año antes, el alza había alcanzado el 57\%, tras el $71 \%$ registrado en 1994. En abril de 1996, la inflación acumulada en los doce meses anteriores ascendía a $86 \%$.

Estas cifras, aunque excesivamente desfavorables en el contexto histórico venezolano, no reflejan la intensidad de las presiones que se ejercían sobre los precios, ya que las autoridades habían optado por un régimen de control oficial de los mismos. Esta política se enfrentaba con la difícil tarea de encubrir las tensiones provocadas por la abundante liquidez y, a intervalos, por las maxidevaluaciones o expectativas de devaluación de la moneda, que redundaban en una caída de la demanda de dinero.

La magnitud de dichas presiones subyacentes queda de manifiesto ante la evolución de los precios tras la liberalización de los controles, impulsada también por las devaluaciones respectivas del bolívar. En 1989 el alza acumulada en doce meses alcanzó en mayo los tres dígitos, por primera vez en la historia de Venezuela, y cerró el año en $81 \%$. La historia se repitió en 1996; en septiembre, cinco meses después del inicio del programa de ajuste, la inflación interanual alcanzaba un nuevo máximo de $115 \%$. En ambas ocasiones, las autoridades se enfrentaban a una escalada inflacionaria cada vez más difícil de controlar sin imponer distorsiones fatales al funcionamiento de la economía.

La evolución del nivel general de precios afectó también a otros precios relativos claves de la economía, las tasas de interés, que registraron valores reales negativos en los dos períodos, desincentivando el ahorro privado y dificultando la labor de intermediación de las entidades financieras. En el último trimestre de 1988, las tasas reales activas y pasivas, en declinación desde 1986, se aproximaban a -40\%. En 1996 eran del mismo orden, si bien la brecha entre las tasas activas y pasivas se había ampliado hasta alcanzar los diez puntos porcentuales aproximadamente.

\section{La economía 'real'}

Si previamente a 1988 y 1996 existían similitudes claras en el plano de los desequilibrios macroeconómicos y otras apreciables en lo tocante a las políticas aplicadas, las dos situaciones presentaban también diferencias significativas en cuanto al desempeño de las variables reales de la economía, producto y empleo. Este desempeño era notablemente peor en el último perío-
GRAF1CO 3

\section{Venezuela: Los vaivenes de la economía, 1987-1996}

(Crecimiento del producto y tasa de desempleo, en porcentajes)

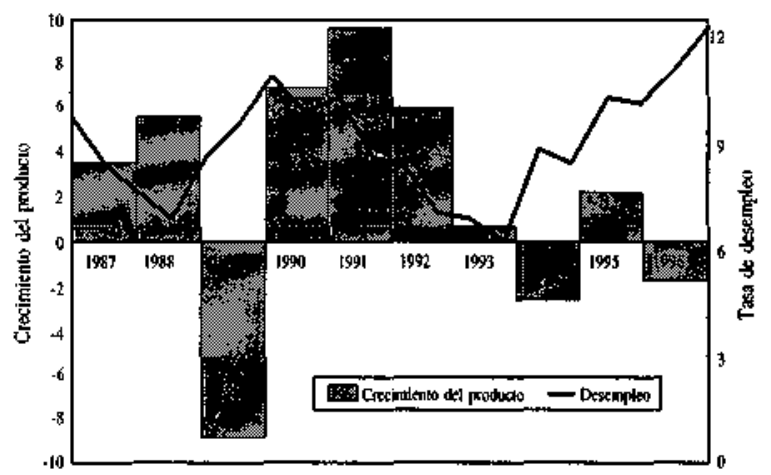

do que en el primero (gráfico 3). No es irrealista suponer que, fuera de los gabinetes de los economistas y del gobierno, aquellas variables incidieron más que los balances del Banco Central y del Ministerio de Hacienda en la percepción general que tenía de la situación la población venezolana.

\section{a) La evolución de la actividad económica}

El crecimiento de la economía tuvo características distintas, tanto cuantitativas como cualitativas, en los meses previos a la adopción de los dos programas de ajuste. Cuantitativamente, el crecimiento fue más alto en 1988, cuando el producto aumentó en casi $6 \%$ pese a la fragilidad que, como ya se indicó, presentaban las bases de ese dinamismo. ${ }^{18}$ Tal resultado seguía a tres años consecutivos de crecimiento tras la crisis de comienzos de los años ochenta, lo que hizo que el PIB recuperara en 1987 el nivel que tenía antes de la crisis. El crecimiento de 1988 permitió elevar en 3\% el producto por habitante. En cambio, en 1994 la actividad cayó en $2.5 \%$ y apenas recuperó en el año siguiente el terreno perdido, con lo que el PIB por habitante empeoró.

Más significativas son las diferencias cualitativas en cuanto a la composición y modalidades del crecimiento económico. En diciembre de 1988 se celebraron elecciones presidenciales. En los meses anteriores,

\footnotetext{
${ }^{18}$ Las cifras sobre crecimiento del producto interno bruto provienen de elaboraciones efectuadas por la CEPAL de las cifras oficiales del país. Estas últimas pueden diferir algo de las presentadas en el texto debido a que la ponderación utilizada tiene un año base distinto.
} 
las autoridades mantuvieron e incluso acentuaron la orientación expansiva que habían impreso a la política económica desde 1986. El gasto fiscal, en especial el destinado a la inversión, se incrementó sensiblemente y la política monetaria se fue relajando en forma paulatina. Como consecuencia, la demanda interna se configuró como el principal factor dinamizador de la actividad económica, lo que se aplica tanto a la demanda pública como a la privada; esta última se dirigió en parte a acumular inventarios ante la incertidumbre generada por la política cambiaria.

Ello provocó una expansión generalizada y a ritmo creciente de la actividad interna con excepción de la extracción de petróleo y gas, afectada por severas restricciones externas, $y$, en menor medida, de la agricultura y el transporte. Si se exceptúa la minería no petrolera, cuyo fuerte crecimiento respondió al empuje de la demanda externa, las demás ramas productoras de bienes respondieron al estímulo del consumo y la inversión internos. El gasto público en infraestructura compensó la contracción de la construcción privada de viviendas y redundó en un crecimiento de $6 \%$ del sector de construcción en su conjunto. La actividad manufacturera se recuperó en $5 \%$ tras el pobre resultado del año precedente, resultando particularmente favorecidas las industrias productoras de bienes de consumo. El sector financiero mostró un gran dinamismo al igual que en el año anterior, como consecuencia de la diversificación de los servicios bancarios ante el estancamiento del mercado crediticio tradicional. La expansión de las adquisiciones de productos constituyó un poderoso estímulo para la actividad comercial. También crecieron, aunque menos, los sectores de servicios sociales y personales.

Con todo, más de la mitad del aumento de la demanda interna se nutrió de productos importados, por lo que el volumen de compras externas aumentó en $20 \%$ y volvió a representar una quinta parte de la oferta total, la fracción más alta desde 1982. Ello contribuyó, a su vez, al desequilibrio del balance de pagos ya mencionado.

El panorama fue radicalmente distinto en 1994 y 1995. En un clima de atonía interna, fue la demanda externa la que impulsó la economía e hizo crecer el producto, aunque levemente, en 1995. En particular, el sector petrolero creció sostenidamente a un ritmo cercano al 6\% anual. En cambio, si bien las inversiones de la industria petrolera en el país estimularon la actividad de algunas industrias nacionales, el sector no petrolero en su conjunto se contrajo significativamente en 1994 y apenas creció, en menos de 1\%, en 1995, resintiéndose del estancamiento o declinación del consumo, especialmente el público, y de la franca caída de las inversiones pública y privada. El conjunto de sectores no transables estuvo en recesión y, de éstos, el peor resultado correspondió a la construcción, que en 1995 se contrajo (en 11\%) por tercer año consecutivo. También se redujo el ritmo de actividad del sector de comercio, restaurantes y hotelería, así como de la fabricación de automóviles.

Estas diferencias en el patrón de crecimiento económico entre los dos períodos incidieron directamente en las condiciones de vida de la población, las cuales, como se verá a continuación, se deterioraron manifestamente en los años previos a 1996, lo que no había ocurrido en 1988.

\section{b) El empleo y los salarios}

En ese último año, la mayor actividad productiva, así como la concentración del crecimiento en sectores fuertemente generadores de empleo (construcción, comercio, etc.) hizo aumentar la ocupación en $6 \%$, llegando así a un incremento acumulado de casi $20 \%$ en tres años. El empleo creció en todos los sectores, salvo la agricultura y la producción de servicios básicos. Con ello, la tasa de desocupación abierta mantuvo su tendencia declinante y disminuyó a 7.3\%, su nivel más bajo desde 1982 y apenas la mitad del registrado cuatro años antes. El descenso fue especialmente pronunciado en el área metropolitana de Caracas y en Guyana, merced, en el caso de esta última región, a las inversiones en obras de infraestructura minera y eléctrica.

En el marco de las habituales negociaciones colectivas, los salarios se reajustaron, en promedio, en $15 \%$ en las ciudades y en $18 \%$ en el campo. Se decretó también un incremento del salario mínimo de $8 \%$. Estos aumentos permitieron compensar en parte el encarecimiento generalizado, a pesar de lo cual el poder adquisitivo de los trabajadores declinó por segundo año consecutivo (11\% los urbanos y $10 \%$ los rurales), pero las mayores posibilidades de ocupación permitieron atenuar el deterioro de los ingresos familiares reales.

Por el contrario, en 1995 la expansión del sector petrolero no fue suficiente para absorber los cerca de 600000 trabajadores que se incorporaron al mercado de trabajo, muchos de ellos impulsados por el deterioro de los salarios reales y de las condiciones de vida en general. Así, aunque aumentó algo el nivel de ocupación, también lo hizo la tasa de desempleo abierto, 
que culminó una trayectoria ascendente llegando a $11 \%$ en todo el país (12\% en las ciudades) a principios de 1996 (gráfico 3).

El empeoramiento de las condiciones de vida de la población también trató de compensarse en 1995 mediante reajustes salariales y medidas específicas del gobierno; entre éstas, se otorgaron subvenciones para los trabajadores del sector privado con menores ingre- sos, se incrementaron, conforme a la normativa laboral, los salarios del sector público en $30 \%$ y se reajustó el salario mínimo urbano, que pasó de 21000 a 31000 bolívares. Sin embargo, dado el ritmo más elevado de la inflación en ese período, tales medidas no pudieron impedir que las remuneraciones reales descendieran en las ciudades en mayor proporción (14\%) que en 1988.

\section{III}

\section{Del Gran Viraje a la Agenda Venezuela}

Los desequilibrios macroeconómicos señalados, similares en los dos períodos, condujeron a los respectivos gobiernos a imponer medidas del mismo corte ortodoxo para estabilizar la economía, ${ }^{19}$ como requisito previo necesario para restablecer la senda del crecimiento sostenido. Los resultados respondieron tanto a las medidas adoptadas como a la reacción que ellas provocaron en la sociedad venezolana, reacción que estuvo a su vez influida, como queda dicho, por la evolución de las variables reales: producción y, sobre todo, empleo.

\section{Mismos males, mismos remedios...}

La piedra angular de los dos programas de ajuste fue la liberalización de la economía: supresión de los controles de precios (con la excepción de algunos productos de primera necesidad), de cambios (permitiendo a la moneda flotar libremente) y de tasas de interés. En el programa de 1989 se estipulaba también la liberalización del comercio exterior, con rebaja de aranceles y eliminación de controles y subsidios; en ese marco, Venezuela ingresó al GATT en septiembre de 1990. Dado que esta situación no se revirtió posteriormente, en el programa de 1996 no figuran medidas de esta índole, manteniéndose así la política de apertura.

La reforma fiscal, orientada a equilibrar las cuentas públicas, fue también un componente básico de los dos programas, ciertamente el que mayor impacto inmediato tuvo en las condiciones de vida de la población y en la reacción de ésta. Entre las medidas para aumentar los ingresos fiscales sobresale, por ser un

\footnotetext{
${ }^{19}$ Véase una comparación sinóptica de los dos programas de ajuste en Bottome (1996).
}

tema especialmente sensible para la población venezolana y por ende de alto voltaje político, la subida de los subvencionados precios de la gasolina, que figuraban entre los más bajos del mundo. Dichos precios se duplicaron en febrero de 1989, mientras que en abril de 1996 casi se quintuplicaron, previéndose en ambos casos reajustes futuros. En 1989 se inició la implantación progresiva de un impuesto sobre el valor agregado, cuya tasa fue elevada del $12.5 \%$ al $16.5 \%$ en virtud del programa de 1996. Se decidió aumentar las tarifas de los servicios públicos de electricidad, agua y recolección de basura (entre 30 y $40 \%$ en 1989 , entre 35 y $65 \%$ en 1996). Se impulsaron las privatizaciones de empresas públicas y activos del Estado. Se anunciaron reformas al sector público, sobresaliendo las relativas al sistema de prestaciones y pensiones (en 1996) y a la regulación del sistema financiero (en 1989); en 1996 se dispuso además la creación de un fondo de capitalización de la banca para contribuir a sanear las instituciones financieras privadas con fondos prestados por el Banco Mundial, entre otros.

Junto con las metas fiscales, los dos programas incluían directrices para la aplicación de una política monetaria restringida que coadyuvara al objetivo de reducir drásticamente la inflación tras la liberación de precios, conforme a las metas pactadas en ambas ocasiones con el Fondo Monetario Internacional.

Una novedad importante del programa de 1996 fue el mayor énfasis puesto en el gasto social, con el que se trataba de mitigar el impacto desfavorable de las medidas en los sectores de escasos recursos, reflejando así una mayor conciencia de la importancia del "factor social" para la viabilidad de las medidas económicas. Entre otras cosas, se contemplaba duplicar la subvención alimentaria ya existente, un conjunto de 
becas dirigido a la capacitación laboral de los jóvenes que no continuaran sus estudios, la duplicación de las pensiones otorgadas por el Instituto Venezolano de la Seguridad Social y un llamado Programa de Alimentos Estratégicos mediante el cual se facilitarían a las familias pobres ciertos alimentos básicos al $60 \%$ de su precio en el mercado. Además, a raíz de la subida de los precios de la gasolina se otorgó una subvención al transporte público de pasajeros para evitar que dicha alza repercutiera en las tarifas del transporte. Estaba previsto que, en conjunto, el gasto social se elevara del equivalente de $0.45 \%$ del PIB al $2 \%$. Muchas de las medidas debían recibir el apoyo financiero del Banco Mundial y del Banco Interamericano de Desarrollo.

\section{2. ...¿distintos resultados?}

La aplicación inicial de ambos programas produjo una aceleración de la inflación y una contracción de la demanda interna que afectó adversamente al crecimiento del producto. La aceleración de la inflación (gráfico 4) tuvo lugar inmediatamente tras la promulgación de las medidas. Después del primer choque, sin embargo, la tasa de inflación mensual comenzó a descender. En 1989, pasó de un máximo de $21.3 \%$ en marzo a $1.7 \%$ en diciembre; en 1996 , de $12.6 \%$ en mayo de ese año a 1.6\% en marzo de 1997.

El ajuste de la producción fue brutal en 1989. El producto interno bruto registró una caída sin precedentes de casi $9 \%$, arrastrado por la contracción de la demanda interna y sobre todo por el derrumbamiento de la inversión, que se redujo en $40 \%$. Casi todos los

GRÁFICO 4

Venezuela: La montaña rusa. Brotes inflacionarios en una década, 1987-1997 (Porcentaje de variación mensual del IPC acumulado en 12 meses)

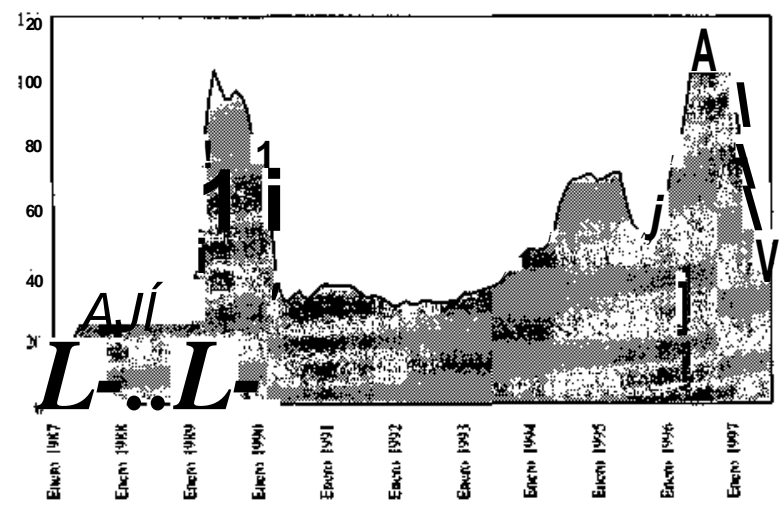

sectores se resintieron del encarecimiento de los insumos, en su mayoría importados, de la eliminación o la reducción de los subsidios y del aumento de las tasas de interés. Sólo se salvaron la industria petrolera, la producción de electricidad y los servicios personales y sociales, que se mantuvieron estancados. La primera se benefició de su orientación hacia los mercados externos, lo que también sucedió a algunos sectores manufactureros, entre ellos los de ciertos productos alimentarios y textiles. Pero el conjunto de la manufactura se contrajo en $10 \%$, siendo la más afectada la industria automotriz, con una caída de $80 \%$ en las ventas internas y una aguda falta de liquidez debido a las pérdidas cambiarias relacionadas con las cartas de crédito contraídas durante el año anterior para pagar las importaciones. También declinó considerablemente la producción de maquinaria, de bienes de consumo duraderos y de insumos para la construcción, paralelamente al retraimiento (en 30\%) de esta última actividad, particularmente afectada por el alza de las tasas de interés.

La merma de la actividad interna redundó en una disminución de la ocupación, pese a que por decreto se prohibieron los despidos hasta diciembre y a que en el último trimestre del año se inició un plan de empleo público de emergencia. Muchos de los desempleados buscaron refugio en el sector informal de la economía, donde la ocupación creció en $7 \%$ en 1989 y en más de $9 \%$ en 1990. La desocupación abierta aumentó en dos puntos porcentuales, afectando en 1989 a más del $9 \%$ de la población activa. La situación se agravó a comienzos de 1990, cuando terminó la vigencia del decreto de inamovilidad laboral, superándose la tasa de $11 \%$ de desempleados.

El ajuste recesivo de la economía fue aparentemente menor en 1996 debido a que, en primer lugar, la actividad económica no petrolera ya acusaba una trayectoria declinante y a que, en segundo lugar, el sector petrolero mantuvo un robusto crecimiento amparado en las favorables condiciones del mercado externo. La caída del producto interno bruto total pudo así contenerse a un $1.6 \%$, si bien el sector no petrolero se contrajo en $3.6 \%$. La ya alta tasa de desempleo urbano, cercana al 11\%, se elevó hasta superar el 12\% en el segundo semestre de 1996. Casi la mitad de la población trabajadora venezolana subsistía en el sector informal de la economía. Las condiciones de vida se tornaron aún más precarias.

Encajado el primer choque, la actividad económica comenzó a recuperarse en ambas ocasiones, lo que 
ocurrió respectivamente en el transcurso de 1990 y en 1997. En aquel año, el producto interno bruto se amplió en $7 \%$, si bien esta recuperación parcial respondió sobre todo a una fuerte expansión de la actividad petrolera (14\%) y de la inversión pública. El repunte del consumo privado fue mucho más tímido y la inversión privada siguió deprimida. La recuperación se confirmó en los dos años siguientes; en 1991, el producto volvió a crecer vigorosamente (en casi 10\%) y en 1992 lo hizo en 6\%. La tasa de desocupación comenzó a descender a partir del segundo semestre de 1990 hasta situarse por debajo de 7\% en 1993.

Sin embargo, la oposición popular al programa económico iniciado en 1989 se tradujo en un clima de inestabilidad política que terminó enrareciendo el ambiente de expectativas en que se sustentaban el consumo y, sobre todo, la inversión privados. A nivel político, las dificultades del gobierno impidieron la aplicación cabal y completa del conjunto de medidas. Las nuevas normas reguladoras de la banca entraron en vigor con considerable retraso, a fines de 1993, demasiado tarde para evitar la crisis del sistema bancario que estalló en diciembre de ese año. La subida de los precios de la gasolina y el proceso de privatización se interrumpieron en febrero de 1992. El proyectado impuesto sobre el valor agregado nunca alcanzó el nivel minorista. Fracasaron todos los intentos de reformar el régimen de prestaciones sociales.

En este clima poco propicio llegó a su fin la fase de auge de los precios del petróleo. Como resultado, la economía perdió su aliento en 1993, con lo que el producto se estancó y todos los componentes del gasto interno anotaron registros negativos. La política económica perdió buena parte de su margen de maniobra y no pudo impedir un alza sustancial de las tasas de interés. En ese contexto, a fin de año se inició una concatenación de quiebras de instituciones bancarias que gravó estrepitosamente el presupuesto del Estado en los meses siguientes. Ante la emergencia, el nuevo gobierno impuso a partir de junio de 1994 controles a las variables clave de la economía: precios, tipo de cambio y tasas de interés. Con ello se cerraba el primer experimento de reforma neoliberal en Venezuela.

¿Correría el segundo la misma suerte? Al cumplirse un año de la promulgación de la Agenda Venezuela, la aplicación del programa de medidas avanzaba ante la reacción estoica de la población. El programa de privatizaciones entraba en su etapa final tras haber sentado ciertos hitos, especialmente la colocación de las acciones estatales de la empresa de telecomunicaciones CANTV, previéndose en los meses siguien- tes la venta de las empresas de los sectores del aluminio, el hierro y el acero. Las medidas económicas habían concitado la confianza de los inversores extranjeros: sustanciales entradas de capitales externos habían convertido a la Bolsa de Caracas en la estrella de los mercados de valores latinoamericanos y, juntamente con la favorable evolución de los precios del petróleo, habían propiciado una ingente acumulación de reservas (que alcanzaron un nivel sin precedentes históricos en agosto de 1997) y sostenido la cotización del bolívar, apreciado en términos reales. Ante esta situación, no había sido necesario desembolsar los dos últimos tramos del crédito contingente pactado con el Fondo Monetario Internacional, organismo que siguió, no obstante, avalando las políticas aplicadas por el gobierno. Varios meses de negociaciones entre el gobierno, los sindicatos y el sector empresarial culminaron en marzo de 1997 con un acuerdo para mejorar la seguridad social y establecer nuevos fondos de pensiones, acuerdo reflejado en junio en una reforma de la Ley Orgánica del Trabajo.

Pero por otro lado, el alto costo social soportado por una resignada población venezolana mantenía vigentes las tensiones sociales. Cuando, en enero de 1997, el país cumplía 39 años de democracia, las universidades públicas se encontraban paralizadas a causa de una huelga de profesores. Los médicos, que habían conseguido un alza de sus sueldos, recurrían al mismo expediente en demanda de material para los hospitales. El gobierno había debido ceder ante análogas reivindicaciones de los funcionarios públicos. Otros sectores profesionales, entre ellos los trabajadores de la empresa CANTV y los maestros, contemplaban acciones de huelga exigiendo mejoras salariales. Dos meses después, los sindicatos salían a las calles de Caracas para pedir mejores salarios y el respeto de los derechos humanos y oponerse a la privatización de las empresas estatales. Una encuesta efectuada en junio del mismo año revelaba un clima de opinión ampliamente desfavorable al gobierno y pesimista en cuanto a las condiciones de vida y sus perspectivas. ${ }^{20}$

Los reajustes salariales del primer semestre de 1997, necesarios para colmar parte del rezago acumulado y aliviar la pesada carga soportada por la población, seguían hipotecando las finanzas públicas, estabilizadas por el momento gracias a la nueva bonanza del mercado petrolero. La asignación de parte de los

211 Latin American Weekly Report, $1997 \mathrm{~b}$. 
recursos extraordinarios obtenidos de esta fuente para financiar el incremento del gasto corriente por aquel concepto arrojaba sombras sobre la credibilidad a largo plazo del ajuste fiscal. En última instancia, no estaba aún claro si la sociedad venezolana podría dejar atrás definitivamente los vaivenes cíclicos que, de la mano de los ingresos petroleros, la han caracterizado desde el decenio de 1970, pasando de fases expansionistas financiadas con esos ingresos a períodos de doloroso ajuste.

\section{IV}

\section{Conclusiones}

En Venezuela, las drásticas reformas de 1989 recayeron en una población que, al ser menos sensible a los desequilibrios macroeconómicos que a las condiciones concretas de la vida cotidiana, no estaba preparada para soportar los sacrificios que se exigían de ella. En efecto, si bien los primeros hacían la reforma necesaria, las segundas no presentaban aún la gravedad que adquirirían algunos años más tarde, por lo que el choque impuesto por la reforma fue excesivo y ésta se tornó políticamente inviable. Anticipar este hecho habría requerido, no ya mantener el statu quo, sino concebir soluciones imaginativas que tuvieran en cuenta la respuesta social y el equilibrio de fuerzas a nivel político.

En 1996, el "costo de oportunidad" de las reformas había disminuido perceptiblemente, pues la población había sufrido en carne propia, en forma de inflación y desempleo, las consecuencias de otras políticas. El empeoramiento inmediato de las condiciones de vida acarreado por las reformas, independientemente de la gravedad absoluta de esas condiciones, fue menos drástico en esa ocasión que en la anterior.

Esta observación sirve para subrayar un hecho en apariencia obvio pero a menudo descuidado o simplemente ignorado, incluso por los políticos y las instituciones financieras internacionales de turno: que las reformas económicas no tienen lugar en el vacío o en un laboratorio esterilizado, sino en un contexto social y político determinado, que interactúa con el contenido económico de las medidas e influye en su viabilidad tanto o más que este último. La evaluación de la viabilidad de las políticas económicas no puede dejar de lado este elemento. Su consideración obliga a tomar en cuenta las circunstancias objetivas a las que se enfrenta la población del país y su percepción subjetiva de esas circunstancias. Si esta labor crucial no atañe a un buen economista, no puede dejar indiferente a un buen político, responsable último de todo cambio social en perspectiva.

La consideración explícita del "factor social" se ha ido pues abriendo paso cuando comienza a hacerse en la región un balance más completo de la experiencia neoliberal. De alguna manera, así lo reconocen organismos multilaterales como el Banco Interamericano de Desarrollo e inequívocamente lo han manifestado personalidades en el ámbito regional. ${ }^{21}$ Los responsables políticos que aún lo ignoran lo hacen a su propio riesgo. En Venezuela, estas consideraciones son determinantes para el logro de un consenso social que permita estabilizar definitivamente la economía en torno a una senda de crecimiento del que nadie quede excluido, superando para siempre las fluctuaciones derivadas de los ciclos del mercado petrolero.

\section{Bibliografía}

Acuña, C. H. y W.C. Smith (1994): The political economy of structural adjustment: The logic of support and opposition to neoliberal reform, W.C. Smith, C.H. Acuña y E.A. Gamarra (eds.), Latin American Political Economy in the Age of Neoliberal Reform: Theoretical and Comparative perspectives for the 1990's, New Brunswick, New Jersey, Transaction Publishers. Bottome, R. (1996): ¿Nuevo comienzo?, Veneconomía mensual, vol. $13, \mathrm{~N}^{\circ} 7$, Caracas, abril.

Bresser, L. C, J. M. Maravall y A. Przeworski (1994): Economic reforms in new democracies: A social-democratic approach,
W.C. Smith, C.H. Acuña y E.A. Gamarra (eds.), Latin American Political Economy in the Age of Neoliberal Reform: Theoretical and Comparative perspectives for the 1990 's, New Brunswick, New Jersey, Transaction Publishers.

\footnotetext{
${ }^{21}$ En este sentido se pronunciaba, por ejemplo, el Ministro de Hacienda de Chile, quien presidía en octubre de 1996 las reuniones del Fondo Monetario Internacional y del Banco Mundial.
} 
Cavarozzi, M.(1994): Politics: A key for the long term in South America, W.C. Smith, C.H. Acuña y E.A. Gamarra (eds.), Latin American Political Economy in the Age of Neoliberal Reform: Theoretical and Comparative perspectives for the 1990's, New Brunswick, New Jersey, Transaction Publishers.

Clairmont, F. F. (1996): The Rise and Fall of Economic Liberalism, Penang, Southbound y Third World Network.

CEPAL (Comisión Económica para América Latina y el Caribe (1997): La brecha de la equidad: América Latina, el Caribe y la cumbre social, LC/G.1954 (CONF. 86/3), Santiago de Chile, 12 de marzo.

(varios años): Estudio Económico de América Latina y el Caribe, Santiago de Chile.

De Janvry, A., A. Fargeix y E. Sadoulet (1991): The political feasibility of rural poverty reduction, Journal of Development Economics, vol. 37, $\mathrm{N}^{\text {os }} 1$ y 2, Amsterdam, Países Bajos, Elsevier Science Publishers, B.V.

Gamarra, E. A. (1994): Market-oriented reforms and democratization in Latin America: Challenges of the 1990s, en W.C. Smith, C.H. Acuña y E.A. Gamarra (eds.), Latin American Political Economy in the Age of Neoliberal Reform: Theoretical and Comparative perspectives for the 1990's, New Brunswick, New Jersey, Transaction Publishers.

Haggard, S. y R. Kaufman (1995): Estado y reforma económica: la iniciación y consolidación de las políticas de mercado, Desarrollo económico, vol. 35, $\mathrm{N}^{\circ}$ 139, Buenos Aires, Instituto de Desarrollo Económico y Social (IDES).

Heredia, B. (1994): Making economic reform politically viable: The mexican experience, Democracy, Markets and Structural Reform in Latin America, Londres, North-South Center.

Kaufman, R. R., C. Bazdresch y B. Heredia (1993): The Politics of Economic Reforms in Mexico: the Solidarity Pact of 19871988, Papers on Latin America, $\mathrm{N}^{\circ} 28$, Nueva York, Columbia University, Institute of Latin American and Iberian Studies.

Keynes, J. M. (1936): The General Theory of Employment, Interest and Money, Nueva York Harcourt, Brace and Company (reimpresión sin fecha).
Latin American Weekly Report (1997a): Is the "fujimorazo"a dead duck?, Londres, Latin American Newsletters, 11 de febrero. (1997b): Londres, Latin American Newsletters, 8 de julio.

Nairn, M. (1993): Paper Tigers and Minotaurs. The Politics of Venezuela's Economic Reforms, Washington D.C., A Carnegie Endowment Book.

Navarro, M.F. (1995): Democracia y reformas estructurales: explicaciones de la tolerancia popular al ajuste económico, Desarrollo Económico, $\mathrm{N}^{\circ} 139$, vol. 35, octubre-diciembre.

Nelson, J. M. (1992): Poverty, equity, and the politics of adjustment, en S. Haggard y R. Kaufman (eds.), The Politics of Economic Adjustment: International Constraints, Distributive Conflicts and the State, Princeton, New Jersey, Princeton University Press.

Przeworski, A. (1993): Democracy and the Market. Political and Economic Reforms in Eastern Europe and Latin America, Londres, Cambridge University Press.

Rodrik, D. (1996): Understanding economic policy reform, Journal of Economic Literature, vol. XXXIV, $\mathrm{N}^{\circ} 1$, Nashville, Tennessee, American Economic Association.

The Economist Intelligence Unit (1997): Country Forecasts (CD ROM), Latin American Business Intelligence, Oxford, Knight Ridder, 2 de mayo.

Vacs, A. C. (1994): Convergence and dissension: Democracy, markets, and structural reform in world perspective, en W.C. Smith, C.H. Acuña y E.A. Gamarra (eds.), Latin American Political Economy in the Age of Neoliberal Reform: Theoretical and Comparative perspectives for the 1990 's. New Brunswick, New Jersey, Transaction Publishers.

Williamson, John (1990): What Washington, D.C., means by policy reforms, J. Williamson (ed.) Latin American Adjustment: How Much Has Happened?, Washington D.C., Institute for International Economics (HE).

(ed.) (1994): The Political Economy of Policy Reform, Washington D.C., HE 